not ensure that long-term environmental considerations are properly taken into account.

In a section entitled "A vision for 2050", Gleick presents an optimistic future, presumably conditional on the timely adoption of appropriate policies. This is a useful exercise, inasmuch as it offers hope rather than gloom. It would have been even more useful, however, had the author mapped out alternative scenarios (at least semi-quantitatively), comparing and contrasting the probable outcomes of specified circumstances (for example, rising or falling energy costs, or climatic changes resulting in increased or reduced availability of water) and policies (pricing of water and other incentives to promote water conservation). Gleick makes much of the concept of basic needs for water, but does not discuss how such needs are conditioned by climate, type of economy or mode of subsistence.

Perhaps the most useful section of the volume is the Data Section, where updated information is given in tabular form. However, in presenting the total renewable freshwater supply for each country, the data are seriously flawed in failing to subtract the volume of flow discharged to downstream countries. As a result, the same volumes of water are counted several times over (as in the case of Ethiopia, Sudan and Egypt, for example). As the data are taken from various sources, critical evaluations of their reliability would also have been helpful.

As this is only the first of what is evidently intended to constitute a series of books to be published every two years, we can only hope that subsequent volumes will provide a more complete coverage of the topics

\section{New in paperback}

\author{
Hunting Dow $\mathbf{n}$ the Universe: The \\ Missing Mass, Primordial Black Holes \\ and Other Dark Matters \\ by Michael Hawkins with Celia Fitzgerald \\ Perseus, $\$ 13$ \\ "...his hypothesis is very likely to be \\ disproved to the satisfaction of any \\ sapient individual. If, on the other hand, \\ his theory is observationally confirmed, \\ then he will without doubt be acclaimed \\ by the establishment, and I will eat this \\ review." William Press, Nature 388, 138 \\ (1997).
}
A bout Face
by Jonathan Cole
MIT Press, \$16.81, £15.85
"Cole believes that facial expressions are the main way to communicate emotion, and to prove his point he has had the ingenious idea of examining the deficits of those who either

and issues that would be properly included under the encompassing title The World's Water.

Daniel Hillel is Professor Emeritus of Environmental Physics and Hydrology,

University of Massachusetts, Amherst,

Massachusetts 01003, USA.

\section{Sounding out two centuries}

\section{Sounds of Our Times: Tw o Hundred Years of Ac oustics \\ by Robert T. Beyer}

Springer: 1999. 444 pp. $\$ 49.95$, 237.50

\section{J.Woodhouse}

The science of sound and vibration has come down in the world during the twentieth century. It occupied a position of pre-eminence in antiquity, with the Pythagorean views of universal harmony and the 'music of the spheres'.

By the nineteenth century it was still in the mainstream of rapidly developing physical science, and many famous names made contributions: scientists like Hermann von Helmholtz, Lord Rayleigh, Gustav Kirchhoff and Joseph Henry, and inventors like Alexander Graham Bell and Thomas Edison. In the twentieth century the subject has lacked the glamour of quantum mechanics, astrophysics or molecular biology, but nevertheless research has continued with accelerating pace.

Robert Beyer's engagingly written history of the subject since 1800 tells the whole story, and may help restore some sparkle to a Cinderella subject. It is liberally supplied

cannot interpret the expressions of others ... or cannot display such expressions themselves." Stuart Sutherland, Nature 390, 458 (1997).

The Universe Below : Dis c overing the Secrets of the DeepSea

by William J. Broad, illustrations by Dimitry Schidlovsky

Simon \& Schuster, \$15, £9.99

The Thermal Warriors: Strategies of Insect S urvival by Bernd Heinrich

Harvard University Press, \$17.95

Visions: How Science w ill Revolutionize the 2 lst Century and Beyond

by Michio Kaku

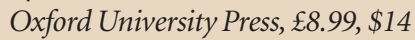

with period illustrations and anecdotes, while maintaining a high standard of technical accuracy and completeness. Among the many gems is the first experimental verification of the formula for the Doppler effect, when the experimental apparatus consisted of a steam locomotive, several trumpeters and some musically trained observers. Beyer also describes the long story of ways to visualize and measure waveforms of sound and vibration - from Helmholtz resonators, tuning-forks and rotating mirrors through the early developments in electromagnetic devices, up to modern electronic and computer-based methods.

During this century the scope of the subject has expanded enormously, with such topics as underwater acoustics, architectural acoustics and ultrasonics. All are covered in Beyer's systematic account, which draws especially on the author's long association with the Acoustical Society of America whose journal and regular conferences provide invaluable raw material, while the society itself is included as part of the history of the subject.

The book comes right up to date with an inevitably brief overview of recent developments and trends across the whole field, from structural vibration to the physiology of hearing. The result is of interest to any scientific reader. Those working in the subject will naturally turn first to the reference list to see if they are mentioned. I wasn't, but I was quite impressed at the choice of modern developments in the areas with which I am familiar.

It would be unrealistic to expect such a general book to give a definitive review of every speciality, but Beyer has made a very creditable stab. This book combines good science with being a good read. It should make its way into many libraries, and onto many bedside tables.

J. Woodhouse is in the Department of Engineering, University of Cambridge, Cambridge CB2 1PZ, UK. 